\title{
PENGARUH HARGA, GAYA HIDUP, DAN FITUR PRODUK TERHADAP KEPUTUSAN PEMBELIAN SMARTPHONE SAMSUNG PADA TOKO NANDA PONSEL AEK NABARA
}

\author{
Raja Saul Marto Hendry, Daslan Simanjuntak \\ Fakultas Ekonomi dan Bisnis Universitas Labuhanbatu \\ Email : rajasaul365@gmail.com
}

\begin{abstract}
ABSTRAK
Penelitian ini bertujuan untuk untuk mengetahui pengaruh harga, gaya hidup, dan fitur produk terhadap keputusan pembelian smartphone Samsung pada Toko Nanda Ponsel Aek Nabara, baik secara parsial maupun simultan. Sampel dalam penelitian ini berjumlah 96 orang yang diambil dengan menggunakan menggunakan metode accidental sampling. Metode analisis yang dipergunakan adalah metode analisis deskriptif, uji asumsi klasik, analisis regresi linier berganda, dan uji hipotesis.

Hasil pengujian hipotesis secara parsial (uji t) menunjukkan bahwa harga $\left(X_{1}\right)$, gaya hidup $\left(X_{2}\right)$, dan fitur produk $\left(X_{3}\right)$ berpengaruh positif dan signifikan terhadap keputusan pembelian smartphone Samsung pada Toko Nanda Ponsel Aek Nabara. Hasil uji hipotesis secara simultan (uji $F$ ) menunjukkan bahwa harga $\left(X_{1}\right)$, gaya hidup $\left(X_{2}\right)$, dan fitur produk $\left(X_{3}\right)$ berpengaruh positif dan signifikan terhadap keputusan pembelian smartphone Samsung pada Toko Nanda Ponsel Aek Nabara. Keputusan pembelian dapat dijelaskan oleh variabel Harga, gaya hidup, dan fitur produk sebesar 50,8\% dan sisanya sebesar 49,2\% dijelaskan variabel lain yang tidak bahas dalam penelitian ini, misalnya : kualitas produk, ekuitas merek, dan sebagainya.
\end{abstract}

Kata kunci : Harga, Gaya Hidup, Fitur produk, Keputusan pembelian.

\section{PENDAHULUAN}

Kebutuhan akan alat komunikasi seperti smartphone sendiri selalu mengalami peningkatan dari tahun ketahun terutama untuk jenis-jenis smartphone dengan merek-merek tertentu. Hal ini dikarenakan pola komunikasi konsumen pada saat ini yang selalu menginginkan sebuah kemudahan dalam komunikasi yang dapat mendukung kegiatan mereka sehari-hari baik dalam pekerjaan maupun hal yang lainnya, oleh karena itu, pilihan konsumen untuk menggunakan smartphone saat ini sangat tinggi seperti salah satunya kenaikan penjualan pada smartphone Samsung. Hal ini terbukti berdasarkan Lembaga riset Gartner penjualan handphone atau smartphone yang mengalami peningkatan dari kuartal kedua 2014 sampai kuartal kedua 2015.

Tabel 1

Data Penjualan dan Market Share Smartphone Dunia pada Kuartal II 2014 dan 2015 (Unit dalam juta)

\begin{tabular}{|l|c|c|c|c|}
\hline \multirow{2}{*}{ Vendor } & \multicolumn{2}{|c|}{ Kuartal II 2015 } & \multicolumn{2}{c|}{ Kuartal II 2014 } \\
\cline { 2 - 5 } & Sales & $\begin{array}{c}\text { Market share } \\
(\mathbf{\%})\end{array}$ & Sales & $\begin{array}{c}\text { Market share } \\
(\mathbf{\%})\end{array}$ \\
\hline Samsung & $71.380,9$ & 31,7 & $45.603,8$ & 29,7 \\
\hline Apple & $31.899,7$ & 14,2 & $28.935,0$ & 18,8 \\
\hline LG Electronics & $11.473,0$ & 5,1 & $5.827,8$ & 3,8 \\
\hline Lenovo & $10.671,4$ & 4,7 & $4.370,9$ & 2,8 \\
\hline ZTE & 9687,6 & 4,4 & $6.331,4$ & 4,1 \\
\hline Lainnya & $90.213,6$ & 40,0 & $62.704,0$ & 40,8 \\
\hline Total & $\mathbf{2 2 5 . 3 2 6 , 2}$ & $\mathbf{1 0 0 , 0}$ & $\mathbf{1 5 3 . 7 7 2 , 9}$ & $\mathbf{1 0 0 , 0}$ \\
\hline
\end{tabular}

Sumber : Gartner (2015) 
Dari Tabel 1 menunjukan bahwa penjualan samsung mengalami peningkatan yang sangat tinggi, Ada yang menarik dari data terbaru penjualan ponsel kuartal kedua yang dirilis Gartner ini, di mana untuk pertama kalinya penjualan smartphone mengalahkan feature phone. Penjualan smartphone terus naik dipicu oleh pesatnya perkembangan smartphone berbasis Android. Gartner mencatat Samsung masih menjadi produsen ponsel pintar terbesar di dunia. Pangsa pasar perusahaan asal Korea Selatan ini mencapai 31,7\%, naik dari 29,7\% pada kuartal kedua 2015. Produsen ponsel pintar terbesar kedua juga masih ditempati Apple. Tetapi pangsa pasar iPhone yang memakai sistem operasi iOS harus mengalami penurunan menjadi 14,2\%, dari 18,8 \% pada kuartal kedua tahun 2014. Setelah Samsung dan Apple, produsen lain yang menempati posisi tiga, empat, dan lima adalah LG (dengan pangsa pasar 5,1\%), Lenovo $(4,7$ $\%)$, dan ZTE (4,3\%).

Sebuah keputusan pembelian yang dilakukan oleh seorang konsumen di lakukan atas dasar keinginan dan kebutuhannya terhadap suatu produk. Keputusan pembelian konsumen meliputi semua proses yang dilalui konsumen dalam mengenali masalah, mencari solusi, mengevaluasi alternatif, dan memilih di antara pilihan-pilihan pembelian mereka. Di era digital seperti saat ini, gaya hidup (life style) menjadi bagian dari kebutuhan sekunder manusia yang bisa berubah tergantung keinginan seseorang untuk mengubahnya. Gaya hidup (life style) secara luas didefinisikan sebagai gaya hidup yang diidentifikasikan oleh bagaimana orang menghabiskan waktu mereka (aktivitas) apa yang mereka anggap penting dalam lingkungannya (ketertarikan), dan apa yang mereka pikirkan tentang diri mereka sendiri dan juga dunia disekitarnya (pendapat). (Setiadi, 2003:148). Gaya hidup ini bisa dinilai relatif tergantung penilaian dari orang lain. Memilki salah satu smartphone ataupun teknologi update ini dapat memberi kepuasaan atau kesenangan atas gaya hidup nya. Perilaku konsumen Indonesia yang unik juga menjadi tantangan tersendiri bagi Samsung, karena di saat OS Android menjadi pemimpin smartphone di berbagai negara di dunia seperti Inggris, Jerman ,Prancis, Italia, Amerika Serikat, dan Australia mengalahkan Blackberry bahkan Apple, hal tersebut justru tidak terjadi di Indonesia. Karena pengguna ponsel di Indonesia memiliki motif yang berbeda dengan pengguna ponsel di negara-negara lain, terutama Amerika, Eropa, atau negara-negara maju salah satunya adalah penerimaan produk berteknologi tinggi sebagai lifestyle.

Harga juga merupakan salah satu faktor konsumen untuk menentukan keputusan pembelian pada produk. Pengaruh harga terhadap keputusan pembelian sangatlah penting, karena dengan tingkat harga yang ditetapkan oleh perusahaan dapat menjadi tolak ukur akan permintaan suatu produk. Penetapan harga yang salah atas suatu produk dapat mengakibatkan jumlah penjualan pada suatu produk tidak dapat maksimal yang mengakibatkan penjualan menurun dan pangsa pasanya berkurang. Oleh sebab itu, dalam penetapan harga perusahaan harus dapat menentukan harga penjualan sesuai dengan pangsa pasar yang dituju agar penjualan produk dan pangsa pasar semakin meningkat. Dalam hal ini, harga Samsung masih lebih terjangkau dibanding kompetitionya seperti Nokia Symbian OS, Blackberry (RIM) dan Apple (iOS).

Fitur produk yang menarik juga menjadi salah satu faktor tingginya penjualan smartphone Samsung. Hal ini disebabkan karena konsumen sudah peka terhadap perkembangan teknologi termasuk teknologi smartphone. Umumnya dikalangan konsumen smartphone digunakan untuk akses sosial media (seperti Facebook, Twitter, Instagram, Path, dan sebagainya), Browsing, dan juga banyak digunakan untuk transaksi belanja di online shop.

\section{TINJAUAN PUSTAKA}

Menurut Kotler dan Keller (2009:181) keputusan pembelian konsumen adalah membeli merek yang paling disukai dari berbagai alternatif yang ada. Pengambilan keputusan 
merupakan suatu kegiatan individu yang secara langsung terlibat dalam mendapatkan dan mempergunakan barang yang ditawarkan. Keputusan pembelian dalam penelitian ini dapat dijelaskan dengan tiga variabel bebas yaitu Gaya Hidup, Harga, dan Kelompok Referensi.

Menurut Kotler dan Amstrong (2008:345), harga adalah sejumlah uang yang ditagihkan atas suatu prosuk atau jasa, atau jumlah dari nilai yang ditukarkan para pelanggan untuk memperoleh manfaat dari memiliki atau menggunakan suatu produk atau jasa. Sepanjang sejarahnya, harga telah menjadi faktor utama yang mempengaruhi pilihan para pembeli. Harga merupakan variabel yang dapat dikendalikan dan menentukan diterima atau tidaknya suatu produk oleh konsumen. Harga semata-mata tergantung pada kebijakan perusahaan, tetapi tentu saja dengan mempertimbangkan beberapa hal. Murah atau mahalnya harga suatu produk sangat relatif sifatnya. Untuk mengatakannya perlu terlebih dahulu dibandingkan dengan harga produk serupa yang diproduksi atau dijual perusahaan lain. Perusahaan perlu memonitor harga yang ditetapkan oleh para pesaing agar harga yang ditentukan oleh perusahaan tidak terlalu tinggi atau sebaliknya, sehingga harga yang ditawarkan dapat menimbulkan keinginan konsumen untuk melakukan pembelian.

Menurut Setiadi (2008:148), Gaya hidup secara luas didefinisikan sebagai gaya hidup yang diidentifikasikan oleh bagaimana orang menghabiskan waktu mereka (aktivitas) apa yang mereka anggap penting dalam lingkungannya (ketertarikan), dan apa yang mereka pikirkan tentang diri mereka sendiri dan juga dunia disekitarnya (pendapat). Gaya hidup merupakan frame of reference yang dipakai sesorang dalam bertingkah laku dan konsekuensinya akan membentuk pola perilaku tertentu. Terutama bagaimana dia ingin dipersepsikan oleh orang lain, sehingga gaya hidup sangat berkaitan dengan bagaimana ia membentuk image di mata orang lain, berkaitan dengan status sosial yang disandangnya. Gaya hidup berimbas pada perilaku konsumsi, dimana ketika seseorang mengkonsumsi atau membeli sesuatu bukan sekedar karena ingin membeli fungsi inheren dari produk tersebut, tetapi juga berkeinginan untuk membeli fungsi sosialnya.

Kotler dan Armstrong (2008:273) mengatakan bahwa fitur menjadi sarana konpetitif untuk mendiferensiasikan produk perusahaan dari pesaing. Fitur yang bernilai baik menjadi cara yang efektif untuk bersaing. Dengan adanya fitur yang menarik dan bermanfaat bagi konsumen, konsumen akan memilih produk tersebut.

Berdasarkan uraian teori di atas, dapat disusun kerangka berpikir sebagai berikut :

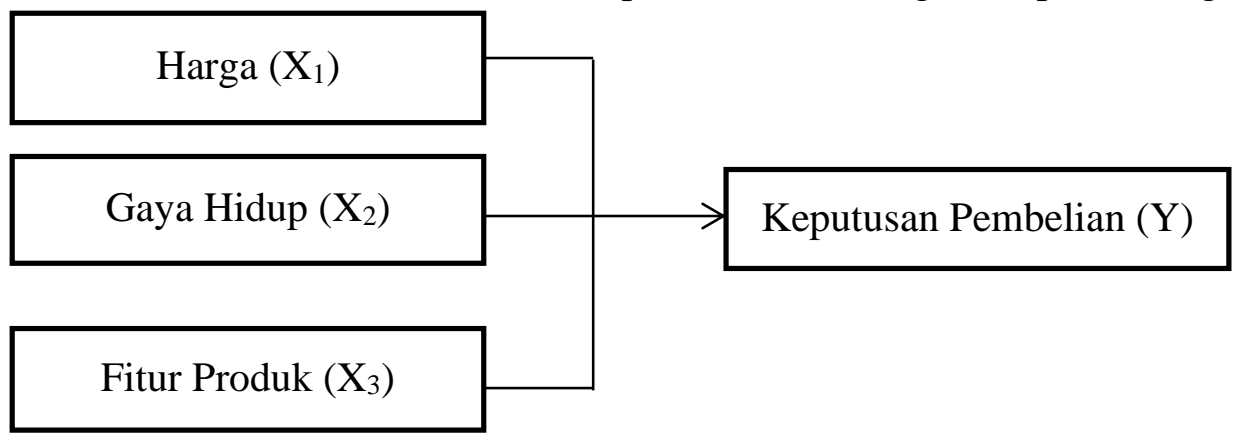

Sumber: Kotler \& Armstrong, 2008, Kotler \& Keller, 2009, Setiadi, 2008 (diolah)

\section{Gambar 1 Kerangka Konseptual}

Berdasarkan atas rumusan masalah yang telah dikemukakan di atas, maka hipotesis yang akan dikembangkan dalam penelitian ini adalah :

1. Harga berpengaruh positif dan signifikan terhadap keputusan pembelian smartphone Samsung pada Toko Nanda Ponsel Aek Nabara. 
2. Gaya hidup berpengaruh positif dan signifikan terhadap keputusan pembelian smartphone Samsung pada Toko Nanda Ponsel Aek Nabara.

3. Fitur produk berpengaruh positif dan signifikan terhadap keputusan pembelian smartphone Samsung pada Toko Nanda Ponsel Aek Nabara.

4. Harga, gaya hidup, dan fitur produk berpengaruh positif dan signifikan terhadap keputusan pembelian smartphone Samsung pada Toko Nanda Ponsel Aek Nabara.

\section{METODE}

\section{A. Populasi dan Sampel Penelitian}

Populasi adalah sekelompok elemen yang lengkap, yang biasanya berupa orang, objek atau kejadian dimana kita tertarik untuk mempelajari suatu objek penelitian (Kuncoro, 2009:115). Populasi dalam penelitian ini adalah konsumen Toko Nanda Ponsel yang jumlahnya tidak dapat ditentukan secara pasti.

Sampel adalah suatu himpunan bagian dari unit populasi (Kuncoro 2009:118). Sampel digunakan untuk mewakili jumlah populasi yang besar. Adanya kendala sumber daya seperti kendala waktu, dana, tenaga, dan sumber daya lain membuat peneliti memerlukan sampel untuk diteliti.

Karena populasi dalam penelitian ini tidak diketahui jumlahnya, menurut Wibisono (dalam Riduwan dan Akdon, 2013 : 255) rumus dalam menghitung sampel pada populasi yang tidak diketahui adalah sebagai berikut :

Keterangan :

$$
n=\left[\frac{Z_{\alpha / 2} \cdot \delta}{\varepsilon}\right]^{2}
$$

$$
\begin{aligned}
\mathrm{n} & =\text { jumlah sampel } \\
\mathrm{Z} \alpha & =\text { nilat tabel } \mathrm{Z}=0,05 \\
\delta & =\text { standar deviasi } \\
\varepsilon \quad & =\text { margin error }
\end{aligned}
$$

Dengan demikian, jumlah sampel dalam penelitian ini adalah :

$$
n=\left[\frac{Z_{\alpha / 2} \cdot \delta}{\varepsilon}\right]^{2}=\left[\frac{(1,96)(0,25)}{0,05}\right]^{2}=96,04 \approx 96 \text { orang }
$$

Teknik pengambilan sampel menggunakan metode Accidental sampling yaitu teknik pengambilan sampel dapat dilakukan kepada siapa saja yang secara kebetulan ditemui dan cocok untuk dijadikan sampel, maka orang tersebut dapat digunakan dengan sebagai sampel.

\section{B. Jenis dan Sumber Data}

Data yang digunakan dalam penelitian ini adalah :

1. Data primer

Data primer adalah data yang diperoleh secara langsung dari sumber asli (tanpa perantara). Data primer yang ada dalam penelitian ini merupakan hasil penyebaran kuesioner pada sampel yang telah ditentukan.

2. Data sekunder

Data sekunder adalah data penelitian yang diperoleh secara tidak langsung dari sumbernya melalui dokumen-dokuemn atau catatan tertulis.

\section{Metode Analisis Data}

\section{Metode Analisis Deskriptif}

Analisis deskriptif adalah kegiatan mengelompokkan, memisahkan, mengatur, mengurutkan, menganalisis serta menyimpulkan data sehingga hasilnya dapat ditafsirkan dan memberikan informasi deskriptif untuk menjawab pertanyaan dari defenisi masalah.

\section{Uji Asumsi Klasik}


Sebelum data dianalisis, maka model regresi berganda harus memenuhi syarat uji asumsi klasik yang terdiri atas :

\section{a. Uji Normalitas}

Uji normalitas dilakukan untuk menguji apakah dalam model regresi, variabel bebas dan variabel terikat atau keduanya telah terdistribusi secara normal atau tidak. Model regresi yang baik adalah model yang memiliki distribusi normal atau mendekati normal. Normalitas dapat dideteksi dengan melihat penyebaran data (titik) dari sumbu diagonal dari grafik atau melihat histogram dari residualnya.

\section{b. Uji Heteroskedastisitas}

Uji model asumsi klasik yang kedua adalah uji heteroskedastisitas. Uji ini dilakukan untuk menguji apakah varians variabel dalam model tidak sama (konstan). Konsekuensi adanya heteroskedastisitas dalam model regresi adalah penaksir (estimator) yang diperoleh tidak efisien, baik dalam sampel kecil ataupun sampel besar, walaupun penaksir yang digunakan menggambarkan populasi (tidak bias) dan bertambahnya sampel yang digunakan akan mendekati nilai sebenarnya (konsisten) ini disebabkan oleh variansnya yang tidak minimum.

Model regresi yang baik adalah bila tidak terjadi heteroskedastisitas. Cara yang dapat dilakukan untuk mendeteksi heteroskedastisitas adalah melihat grafik scatterplot antara nilai prediksi (*ZPRED) dengan nilai residualnya (*ZRESID). *ZPRED dan *ZRESID merupakan nilai prediksi dan residual yang telah distandarisasi. Nilainya memang berubah, tetapi skalanya tidak, sehingga tetap mencerminkan data sesungguhnya (Usman dan Sobari, 2013:78). Indikasi terjadinya heterosdekastisitas dapat dilihat bila terjadi pola sistematik tertentu pada plot seperti titik-titik yang membentuk pola yang teratur, namun bila tidak terdapat pola yang jelas serta titik-titik nya menyebar maka bisa diindikasikan model regresi bebas dari heterosdekastisitas.

\section{c. Uji Multikoliniearitas}

Uji model asumsi klasik selanjutnya adalah uji multikoliniearitas. Uji ini dilakukan untuk mengetahui apakah ada korelasi antara variabel independennya (Usman dan Sobari, 2013:75). Konsekuensi penting bagi model regresi yang mengandung multikolinieritas adalah kesalah standar estimasi akan cenderung meningkat dengan bertambahnya variabel independen, tingkat signifikansi untuk menolak hipotesis nol akan semakin besar, dan probabilitas menerima hipotesis yang salah juga akan semakin besar. Pengujian multikolniearitas dalam penelitian ini dilakukan dengan melihat nilai dari Variance Inflation Factor (VIF) dan nilai Tolerance-nya. Jika nilai VIF $<5$ dan nilai Tolerance-nya $>0,1$ maka tidak terjadi multikoliniearitas.

\section{Analisis Regresi Linear Berganda}

Analisis regresi linear berganda digunakan untuk menganalisis seberapa besar pengaruh dan hubungan antara variabel bebas dengan variabel terikat. Analisis regresi berganda digunakan karena jumlah variabel bebas yang akan diteliti berjumlah lebih dari satu variabel. Dalam penelitian ini peneliti menggunakan aplikasi SPSS 20 for Windows untuk menghitung model regresi berganda ini. Rumus matematisnya adalah :

$$
\begin{aligned}
& \mathbf{Y = a}+\mathbf{b}_{1} \mathbf{X}_{\mathbf{1}}+\mathbf{b}_{2} \mathbf{X}_{\mathbf{2}}+\mathbf{b}_{3} \mathbf{X}_{\mathbf{3}}+\boldsymbol{e} \\
& \text { Dimana : } \\
& \mathrm{Y} \quad=\text { Keputusan Pembelian } \\
& \mathrm{a} \quad=\text { Konstanta } \\
& \mathrm{b}_{1}-\mathrm{b}_{3}=\text { Koefisien regresi } \\
& \mathrm{X}_{1} \quad=\text { Harga } \\
& \mathrm{X}_{2}=\text { Gaya hidup } \\
& \mathrm{X}_{3}=\text { Fitur Produk } \\
& e \quad=\text { Standar error }
\end{aligned}
$$

\section{Pengujian Hipotesis}




\section{a. Uji Signifikansi Parsial (Uji t)}

Uji t pada dasarnya menunjukkan seberapa jauh pengaruh satu variabel independen secara individual dalam menerangkan variasi variabel dependen (Kuncoro, 2009:238). Uji t dalam penelitian ini bertujuan untuk melihat secara parsial apakah variabel $\mathrm{X}$ yaitu harga $\left(\mathrm{X}_{1}\right)$, gaya hidup $\left(\mathrm{X}_{2}\right)$, dan fitur produk $\left(\mathrm{X}_{3}\right)$ berpengaruh signifikan terhadap keputusan pembelian (Y). Bentuk pengujiannya adalah :

- $\mathrm{H}_{0}$ : bi $=0$, artinya secara parsial tidak terdapat pengaruh yang signifikan antara harga $\left(\mathrm{X}_{1}\right)$, gaya hidup $\left(\mathrm{X}_{2}\right)$, dan fitur produk $\left(\mathrm{X}_{3}\right)$ terhadap keputusan pembelian $(\mathrm{Y})$.

- $\mathrm{H}_{\mathrm{a}}$ : bi $\neq 0$, artinya secara parsial terdapat pengaruh yang signifikan antara harga $\left(\mathrm{X}_{1}\right)$, gaya hidup $\left(\mathrm{X}_{2}\right)$, dan fitur $\quad$ produk $\left(\mathrm{X}_{3}\right)$ terhadap keputusan pembelian $(\mathrm{Y})$.

Dalam melakukan uji parsial (uji t), peneliti menggunakan alat bantu aplikasi SPSS 20.0 for Windows. Kriteria pengambilan keputusan, yaitu :

- $\mathrm{H}_{0}$ diterima apabila nilai $\mathrm{t}_{\text {hitung }}<\mathrm{t}_{\text {tabel }}$, dan Sig $>0,05$.

- $\mathrm{H}_{\mathrm{a}}$ diterima apabila nilai $\mathrm{t}_{\text {hitung }}>\mathrm{t}_{\text {tabel }}$, dan $\mathrm{Sig}<0,05$

b. Uji Signifikansi Simultan (Uji F)

Uji F secara mendasar menunjukkan apakah semua variabel bebas yang dimasukkan dalam model mempunyai pengaruh secara bersama-sama terhadap variabel dependen (Kuncoro, 2009:239). Uji F dalam penelitian ini bertujuan untuk melihat apakah variabel X yaitu harga $\left(X_{1}\right)$, gaya hidup $\left(X_{2}\right)$, dan fitur produk $\left(X_{3}\right)$ secara bersama (simultan) berpengaruh signifikan terhadap keputusan pembelian (Y). Bentuk pengujiannya adalah :

- $\mathrm{H}_{0}: \mathrm{b}_{1}=\mathrm{b}_{2}=\mathrm{b}_{3}=0$, artinya secara bersama-sama (simultan) tidak terdapat pengaruh yang signifikan antara harga $\left(\mathrm{X}_{1}\right)$, gaya hidup $\left(\mathrm{X}_{2}\right)$, dan fitur produk $\left(\mathrm{X}_{3}\right)$ terhadap keputusan pembelian (Y).

- Ha $: b_{1} \neq b_{2} \neq b_{3} \neq 0$, artinya secara bersama-sama (simultan) terdapat pengaruh yang signifikan antara harga $\left(\mathrm{X}_{1}\right)$, gaya hidup $\left(\mathrm{X}_{2}\right)$, dan fitur produk $\left(\mathrm{X}_{3}\right)$ terhadap keputusan pembelian (Y).

Dalam melakukan uji parsial (uji F), peneliti menggunakan alat bantu aplikasi SPSS 20.0 for Windows. Kriteria pengambilan keputusan yaitu :

- $\mathrm{H}_{0}$ diterima apabila nilai $\mathrm{F}_{\text {hitung }}<\mathrm{F}_{\text {tabel, }}$, dan nilai $\mathrm{Sig}>0,05$.

- $\mathrm{H}_{\mathrm{a}}$ diterima apabila nilai $\mathrm{F}_{\text {hitung }}>\mathrm{F}_{\text {tabel }}$, dan nilai $\mathrm{Sig}<0,05$.

c. Koefisien Determinasi $\left(\boldsymbol{R}^{2}\right)$

Koefisien determinasi $\left(R^{2}\right)$ pada dasarnya mengukur seberapa jauh kemampuan suatu model dalam menerangkan variase variabel terikat. Nilai koefisien determinasi adalah di antara nol dan satu. Nilai $R^{2}$ yang kecil memberi arti bahwa kemampuan variabel bebas dalam menjelaskan variasi variabel terikat amat terbatas. Sedangkan bila nilai $R^{2}$ besar (mendekati 1 ) berarti variabel bebas memberikan hampir semua informasi yang dibutuhkan untuk memprediksi variasi variabel dependen.

Kelemahan mendasar koefesien determinasi adalah bias terhadap jumlah variabel independen yang dimasukkan ke dalam model. Setiap tambahan satu variabel independen maka $R^{2}$ pasti meningkat tidak peduli apakah variabel tersebut berpengaruh signifikan terhadap variabel dependen. Oleh karena itu penelitian ini menggunakan Adjusted $R^{2}$ saat mengevaluasi model regresi. Tidak seperti $R^{2}$, nilai Adjusted $R^{2}$ dapat naik atau turun apabila satu variabel independen ditambahkan. Hasil penghitungan Adjusted $R^{2}$ dapat dilihat pada output Model Summary. Pada kolom Adjusted $R^{2}$ dapat diketahui berapa persentase yang dapat dijelaskan variabel independen terhadap variabel dependen dan sisanya dijelaskan atau dipengaruhi oleh variabel lain yang tidak dimasukkan dalam penelitian ini.

\section{HASIL DAN PEMBAHASAN}




\section{A. Hasil Uji Asumsi Klasik}

Uji asumsi klasik merupakan uji yang dilakukan untuk melihat apakah suatu model sudah layak atau belum untuk dimasukkan dalam penelitian. Model yang baik adalah model yang sudah memenuhi syarat berikut :

\section{Uji Normalitas}

Uji normalitas untuk melihat apakah nilai residual telah terdistribusi normal. Uji normalitas dapat dilakukan dengan 2 cara yaitu :

1) Analisis Grafik

Dasar pengambilan keputusan untuk Uji Normalitas adalah jika data menyebar disekitar garis diagonal dan mengikuti arah garis diagonal atau grafik histogramnya menunjukkan pola distribusi normal maka model regresi memenuhi asumsi normalitas.

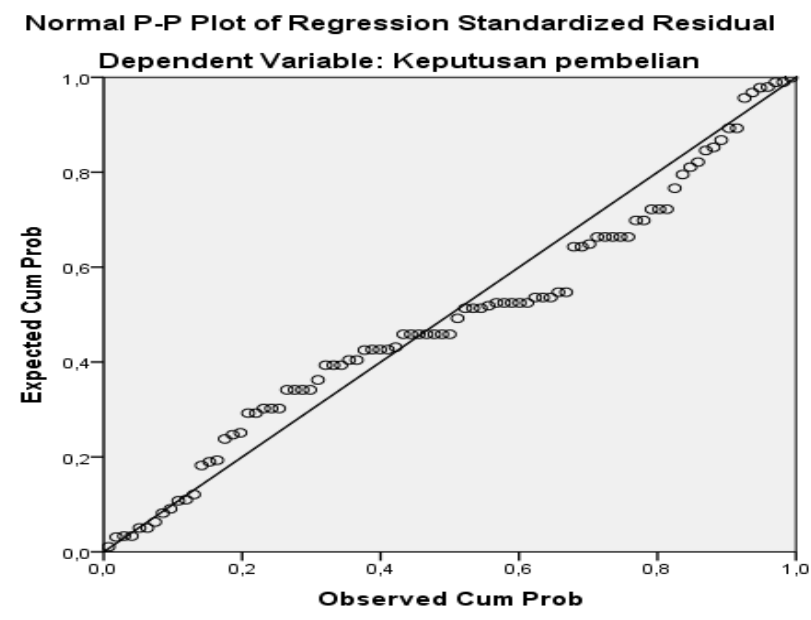

Sumber : Hasil Penelitian, 2016 (Data diolah dengan SPSS)

Gambar 2 Grafik P-Plot Uji Normalitas

Pada gambar 2 grafik P-Plot menunjukkan bahwa data berada di sekitar garis diagonal dan membentuk pola yang mengikuti garis diagonal. Hal ini menunjukkan bahwa data memenuhi asumsi normalitas.

2) Uji Kolmogorov-Smirnov

Uji normalitas juga bisa dilakukan dengan analisis Kolmogorov-Smirnov. Kriteria keputusan yang diambil adalah jika nilai Asymp. Sig. (2-tailed) >0,05 maka tidak mengalami gangguan distribusi normal.

Tabel 2

Hasil Uji Kolmogorov-Smirnov

One-Sample Kolmogorov-Smirnov Test

\begin{tabular}{|ll|r|}
\hline & & $\begin{array}{c}\text { Unstandardized } \\
\text { Residual }\end{array}$ \\
\hline N & Mean & 89 \\
Normal Parameters & 0E-b &, 61689150 \\
& Std. Deviation &, 126 \\
Most Extreme Differences & Absolute &, 126 \\
& Positive &,- 087 \\
Kolmogorov-Smirnov Z & Negative & 1,191 \\
Asymp. Sig. (2-tailed) & &, 117 \\
\hline
\end{tabular}

a. Test distribution is Normal.

b. Calculated from data.

Sumber : Hasil Penelitian, 2016 (Data diolah dengan SPSS)

Pada tabel 2 dapat dilihat nilai Asymp.sig (2-tailed) adalah 0,117 dimana nilainya lebih besar daripada 0,05 . Hal ini menunjukkan bahwa model regresi telah memenuhi asumsi normalitas. 


\section{b. Uji Heteroskedostisitas}

Uji ini dilakukan untuk menguji apakah varians variabel dalam model tidak sama (konstan). Uji ini dapat dilakukan dengan melihat grafik scatterplot.

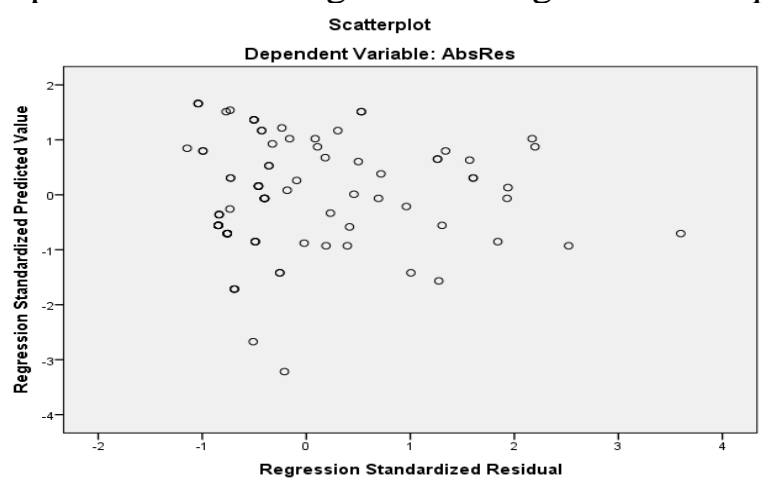

Sumber : Hasil Penelitian, 2016 (Data diolah SPSS)

Gambar 3 Scatterplot

Gambar 3 menunjukkan bahwa pola titik pada scatterplot menyebar di atas titik 0 dan tidak membentuk pola tertentu. Hal ini mengindikasikan bahwa model regresi tidak mengalami masalah heteroskedastisitas. Uji lain yang dapat dilakukan untuk melihat masalah heteroskedastisitas adalah Uji Glejser. Uji Glejser mengusulkan untuk meregresi nilai absolute residual terhadap variabel independen dengan persamaan regresi. Uji Glejser dilakukan dengan melihat nilai signifikansi variabel. Jika nilai signifikansi variabel > 0,05 maka tidak terdapat masalah heteroskedastisitas.

Tabel 3

Hasil Uji Glejser

Coefficients $^{a}$

\begin{tabular}{|c|c|c|c|c|c|c|}
\hline \multirow{2}{*}{\multicolumn{2}{|c|}{ Model }} & \multicolumn{2}{|c|}{ Unstandardized Coefficients } & Standardized & \multirow[t]{2}{*}{$\mathrm{t}$} & \multirow[t]{2}{*}{ Sig. } \\
\hline & & B & Std. Error & Beta & & \\
\hline \multirow{4}{*}{1} & (Constant) &,- 186 & 852 & &,- 219 & ,827 \\
\hline & Harga & ,045 & ,028 & 192 & 1,625 & , 108 \\
\hline & Gaya hidup &,- 074 & ,042 &,- 207 & $-1,760$ & ,082 \\
\hline & Fitur produk & ,072 & ,051 & , 152 & 1,406 & , 163 \\
\hline
\end{tabular}

a. Dependent Variable: AbsRes

Sumber : Hasil Penelitian, 2016 (Data diolah SPSS)

Pada tabel 3 dapat dilihat bahwa nilai Sig dari harga $(0,108)$, gaya hidup $(0,082)$, dan fitur produk $(0,163)$ lebih besar dari 0,05 . Hal ini menunjukkan bahwa model regresi tidak mengalami masalah heteroskedastisitas.

\section{c. Uji Multikolinearitas}

Uji multikoliniearitas bertujuan untuk menguji apakah terjadi korelasi yang tinggi diantara variabel bebas. Model regresi yang baik adalah model yang tidak mengalami multikoliniearitas. Uji ini dilakukan dengan melihat nilai Tolerance dan Variance Inflation Factor (VIF). Jika nilai Tolerance $>0,1$ dan VIF $<5$ maka model memenuhi asumsi multikoliniearitas. Nilai Tolerance dan VIF dapat dilihat pada tabel 4

\section{Tabel 4}

\section{Hasil Uji Multikolinearitas}

Coefficients $^{a}$

\begin{tabular}{|c|c|c|c|c|c|c|c|}
\hline \multirow[t]{2}{*}{ Model } & \multicolumn{2}{|c|}{ Unstandardized Coefficients } & \multirow{2}{*}{$\begin{array}{c}\begin{array}{c}\text { Standardized } \\
\text { Coefficients }\end{array} \\
\text { Beta }\end{array}$} & \multirow[t]{2}{*}{$\mathrm{t}$} & \multirow[t]{2}{*}{ Sig. } & \multicolumn{2}{|c|}{ Collinearity Statistics } \\
\hline & B & Std. Error & & & & Tolerance & VIF \\
\hline (Constant) & 5,017 & 1,324 & & 3,789 &, 000 & & \\
\hline Harga & ,162 & ,043 & ,317 & 3,762 & , 000 & ,730 & 1,369 \\
\hline
\end{tabular}




\begin{tabular}{|r|r|r|r|r|r|r|r|}
\hline Gaya hidup &, 286 &, 065 &, 368 & 4,377 &, 000 &, 734 & 1,362 \\
Fitur produk &, 264 &, 079 &, 256 & 3,325 &, 001 &, 873 & 1,145 \\
\hline
\end{tabular}

a. Dependent Variable: Keputusan pembelian

Sumber : Hasil Penelitian, 2016 (Data diolah dengan SPSS)

Pada Tabel 4 menunjukkan nilai Tolerance $>0,1$ dan nilai VIF $<5$ yang artinya tidak terjadi masalah multikoliniearitas pada model regresi.

\section{B. Hasil Analisis Regresi Linear Berganda}

Analisis regresi linear berganda ditujukan untuk mengetahui pengaruh atau hubungan variabel bebas $\left(\mathrm{X}_{1}, \mathrm{X}_{2}\right.$, dan $\left.\mathrm{X}_{3}\right)$ yaitu variabel kualitas produk, desain produk, dan fitur produk terhadap variabel terikat $(\mathrm{Y})$ berupa keputusan pembelian. Maka untuk memperoleh hasil yang lebih akurat, peneliti menggunakan bantuan program software SPSS (Statistik Product and Service Solution) versi 20.0 dari tabel coefficient maka dihasilkan output sebagai berikut :

\section{Tabel 5}

\section{Hasil Analisis Regresi Berganda}

Coefficients $^{\mathrm{a}}$

\begin{tabular}{|c|c|c|c|c|c|c|}
\hline \multirow{2}{*}{\multicolumn{2}{|c|}{ Model }} & \multicolumn{2}{|c|}{ Unstandardized Coefficients } & Standardized & \multirow[t]{2}{*}{$\mathrm{t}$} & \multirow[t]{2}{*}{ Sig. } \\
\hline & & B & Std. Error & Beta & & \\
\hline \multirow{4}{*}{1} & (Constant) & 5,017 & 1,324 & & 3,789 & ,000 \\
\hline & Harga & ,162 & ,043 & ,317 & 3,762 & ,000 \\
\hline & Gaya hidup & ,286 & ,065 & ,368 & 4,377 & ,000 \\
\hline & Fitur produk & ,264 & ,079 & ,256 & 3,325 &, 001 \\
\hline
\end{tabular}

a. Dependent Variable: Keputusan pembelian

Sumber : Hasil Penelitian, 2016 (Data diolah SPSS)

Berdasarkan Tabel 5 pada kolom Unstandardized Coefficients bagian B diperoleh nilai sebagai berikut :

a) Konstanta (a) $=5,017$. Ini mempunyai arti bahwa jika harga, gaya hidup, dan fitur produk dianggap tidak ada (bernilai nol), maka keputusan pembeli konsumen sebesar 5,017.

b) Koefisien $X_{1}\left(b_{1}\right)=0,162$. Artinya jika harga meningkat satu satuan dan variabel lainnya dianggap konstan, maka keputusan pembelian akan meningkat sebesar 0,162.

c) Koefisien $\mathrm{X}_{2}\left(\mathrm{~b}_{2}\right)=0,286$. Artinya jika gaya hidup meningkat satu satuan dan variabel lainnya dianggap konstan, maka keputusan pembelian akan meningkat sebesar 0,286.

d) Koefisien $X_{3}\left(b_{3}\right)=0,264$. Artinya jika fitur produk meningkat satu satuan dan variabel lainnya dianggap konstan, maka keputusan pembelian akan meningkat sebesar 0,264.

Dengan demikian, persamaan regresi yang dihasilkan adalah sebagai berikut :

$$
Y=5,017+0,162 X_{1}+0,286 X_{2}+0,264 X_{3}+e
$$

\section{Hasil Pengujian Hipotesis}

\section{a. Uji Signifikansi Parsial (Uji t)}

Uji t digunakan untuk mengetahui sejauhmana pengaruh variabel bebas $\left(\mathrm{X}_{1}, \mathrm{X}_{2}\right.$, dan $\mathrm{X}_{3}$ ) secara parsial terhadap variabel terikat (Y). Uji t dilakukan dengan cara membandingkan nilai thitung dengan $t_{\text {tabel }}$. Nilai tabel yang digunakan adalah nilai $t$ pada derajat kebebasan $(\mathrm{df})=$ $\mathrm{n}-\mathrm{k}=96-4=92$ dengan $\alpha=0,05$ yaitu $1,66159=1,662$.

\section{Tabel 6}

Hasil Uji Parsial (Uji t)

Coefficients $^{\mathrm{a}}$

\begin{tabular}{|l|r|r|r|r|r|}
\hline \multicolumn{1}{|l|}{ Model } & \multicolumn{2}{|c|}{ Unstandardized Coefficients } & \multicolumn{1}{c|}{$\begin{array}{c}\text { Standardized } \\
\text { Coefficients }\end{array}$} & \multirow{2}{*}{ Sig. } \\
\cline { 2 - 4 } & \multicolumn{1}{|c|}{$\mathrm{B}$} & Std. Error & \multicolumn{1}{c|}{ Beta } & \\
\hline \multirow{2}{*}{1 (Constant) } & 5,017 & 1,324 & & 3,789 &, 000 \\
Harga &, 162 &, 043 &, 317 & 3,762 &, 000 \\
Gaya hidup &, 286 &, 065 &, 368 & 4,377 &, 000
\end{tabular}




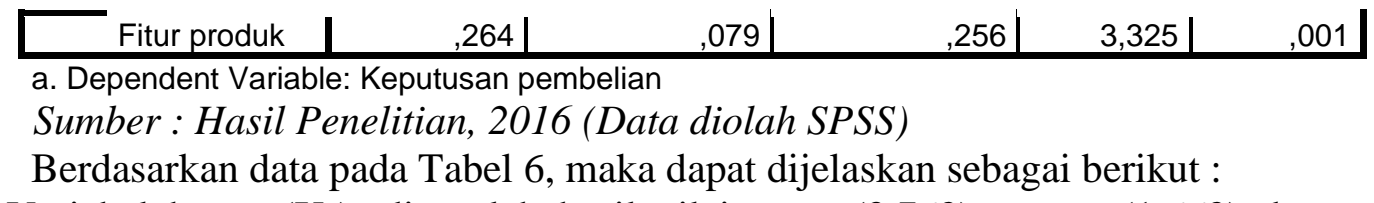

a) Variabel harga $\left(X_{1}\right)$, diperoleh hasil nilai thitung $(3,762)>t_{\text {tabel }}(1,662)$ dengan taraf signifikansi $(0,00)<(0,05)$. Artinya bahwa variabel harga $\left(\mathrm{X}_{1}\right)$ secara parsial berpengaruh positif dan signifikan terhadap keputusan pembelian smartphone Samsung pada Toko Nanda Ponsel Aek Nabara. Dengan demikian hipotesis diterima.

b) Variabel gaya hidup $\left(X_{2}\right)$, diperoleh hasil nilai thitung $(4,377)>t_{\text {tabel }}(1,662)$ dengan taraf signifikansi $(0,00)<(0,05)$. Artinya bahwa variabel gaya hidup $\left(\mathrm{X}_{2}\right)$ secara parsial berpengaruh positif dan signifikan terhadap keputusan pembelian smartphone Samsung pada Toko Nanda Ponsel Aek Nabara. Dengan demikian hipotesis diterima.

c) Variabel fitur produk $\left(X_{3}\right)$, diperoleh hasil nilai $t_{\text {hitung }}(3,325)>t_{\text {tabel }}(1,662)$ dengan taraf signifikansi $(0,00)<(0,05)$. Artinya bahwa variabel fitur produk $\left(\mathrm{X}_{3}\right)$ secara parsial berpengaruh positif dan signifikan terhadap keputusan pembelian smartphone Samsung pada Toko Nanda Ponsel Aek Nabara. Dengan demikian hipotesis diterima.

\section{b. Uji Signifikansi Simultan (Uji F)}

Uji $F$ digunakan untuk mengetahui apakah semua variabel bebas $\left(\mathrm{X}_{1}, \mathrm{X}_{2}\right.$, dan $\left.\mathrm{X}_{3}\right)$ yang dimasukkan dalam model mempunyai pengaruh secara bersama-sama terhadap variabel terikat (Y).

Kriteria pengambilan keputusan adalah :

- $\mathrm{H}_{0}$ diterima jika $\mathrm{F}_{\text {hitung }}<\mathrm{F}_{\text {tabel }}$ pada $\alpha=5 \%$.

- Ha diterima jika $F_{\text {hitung }}>F_{\text {tabel }}$ pada $\alpha=5 \%$.

Nilai $F_{\text {hitung }}$ diperoleh dari hasil SPSS, dan nilai $\mathrm{F}_{\text {tabel }}$ yang digunakan adalah nilai $\mathrm{F}$ dengan derajat kebebasan (df) pada $\mathrm{df}_{1}=4-1=3$, dan $\mathrm{df}_{2}=96-4=92, \alpha=0,05$ yaitu 2,70.

Tabel 7

Hasil Uji Simultan (Uji F)

ANOVA $^{a}$

\begin{tabular}{|rl|r|r|r|r|r|}
\hline Model & & Sum of Squares & Df & Mean Square & F & Sig. \\
\hline \multirow{2}{*}{1} & Regression & 39,580 & 3 & 13,193 & 33,644 &, $000^{\mathrm{b}}$ \\
& Residual & 36,077 & 92 &, 392 & & \\
& Total & 75,656 & 95 & & & \\
\hline
\end{tabular}

a. Dependent Variable: Keputusan pembelian

b. Predictors: (Constant), Fitur produk, Gaya hidup, Harga

Sumber : Hasil Penelitian, 2016 (Data diolah SPSS)

Berdasarkan hasil pengelolaan data yang ditunjukkan pada tabel 7 dapat dilihat bahwa

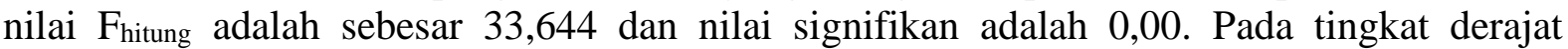
kepercayaan 95\% $(\alpha=5 \%)$ nilai $F_{\text {tabel }}$ adalah sebesar 2,70. Maka berdasarkan tabel 4.11 nilai $F_{\text {hitung }}(33,644)>F_{\text {tabel }}(2,70)$ dan nilai signifikan $(0,00)<(0,05)$. Artinya bahwa variabel harga $\left(\mathrm{X}_{1}\right)$, gaya hidup $\left(\mathrm{X}_{2}\right)$, dan fitur produk $\left(\mathrm{X}_{3}\right)$ secara simultan atau bersama-sama berpengaruh positif dan signifikan terhadap keputusan pembelian smartphone Samsung pada Toko Nanda Ponsel Aek Nabara. Dengan demikian hipotesis diterima.

\section{c. Koefisien Determinasi $\left(\boldsymbol{R}^{2}\right)$}

Pengujian koefisien determinasi $\left(R^{2}\right)$ dimaksudkan untuk melihat seberapa besar variabel keputusan pembelian smartphone Samsung pada dapat dijelaskan oleh ketiga variabel bebas yaitu variabel harga $\left(\mathrm{X}_{1}\right)$, gaya hidup $\left(\mathrm{X}_{2}\right)$, dan fitur produk $\left(\mathrm{X}_{3}\right)$. Tabel koefisien determinasi dapat dilihat pada tabel 8

Tabel 4.12

Koefisien Determinasi

Model Summary 


\begin{tabular}{|c|c|c|c|c|}
\hline Model & $\mathrm{R}$ & R Square & $\begin{array}{l}\text { Adjusted R } \\
\text { Square }\end{array}$ & $\begin{array}{l}\text { Std. Error of the } \\
\text { Estimate }\end{array}$ \\
\hline 1 &, $723^{a}$ &, 523 &, 508 & ,626 \\
\hline
\end{tabular}

Pada tabel 8 dapat dilihat nilai Adjusted $R$ Square sebesar 0,508. Hal ini menunjukkan bahwa variabel keputusan pembelian dapat dijelaskan oleh variabel harga, gaya hidup, dan fitur produk sebesar $50,8 \%$ dan sisanya sebesar $49,2 \%$ dijelaskan variabel lain yang tidak diikutsertakan dalam penelitian ini.

\section{KESIMPULAN DAN SARAN}

\section{A. Kesimpulan}

Berdasarkan hasil analisis yang telah dilakukan, maka penulis dapat mengambil beberapa kesimpulan sebagai berikut :

1. Harga berpengaruh positif dan signifikan secara parsial terhadap keputusan pembelian smartphone Samsung pada Toko Nanda Ponsel Aek Nabara.

2. Gaya hidup berpengaruh positif dan signifikan secara parsial terhadap keputusan pembelian smartphone Samsung pada Toko Nanda Ponsel Aek Nabara.

3. Fitur produk berpengaruh positif dan signifikan secara parsial terhadap keputusan pembelian smartphone Samsung pada Toko Nanda Ponsel Aek Nabara.

4. Harga, gaya hidup, dan fitur produk secara simultan (bersama-sama) berpengaruh positif dan signifikan terhadap keputusan pembelian smartphone Samsung pada Toko Nanda Ponsel Aek Nabara.

5. Keputusan pembelian dapat dijelaskan oleh variabel Harga, gaya hidup, dan fitur produk sebesar 50,8\% dan sisanya sebesar 49,2\% dijelaskan variabel lain yang tidak bahas dalam penelitian ini, misalnya : kualitas produk, ekuitas merek, dan sebagainya.

\section{B. Saran}

Berdasarkan hasil penelitian yang telah didapat, maka penulis dapat memberikan beberapa saran sebagai berikut :

1. Pertimbangan utama perusahaan dalam menetapkan harga harus menyesuaikan spesifikasi yang diberikan dan kualitas produk. Dengan pertimbangan harga yang sesuai, akan menciptakan keputusan pembelian. Disarankan juga kepada perusahaan Samsung dan distributor untuk lebih mempertahankan nilai harga sekarang dan mempertinggi kualitasnya sehingga dapat mempengaruhi sisi fungsional dari setiap calon konsumennya.

2. Disarankan kepada perusahaan Samsung dan distributornya untuk dapat mempengaruhi sisi emosional setiap calon konsumennya dengan mengikuti trend strategi pemasaran terbaru yang dinamakan new wave marketing yang lebih mempengaruhi sisi emosional dengan mengetahui kebutuhan dari calon konsumennya dibandingkan hanya mempromosikan kegunaan dan fungsi-fungsi produk secara teknikal.

3. Penelitian ini hanya terbatas pada tiga variabel bebas yang diukur pengaruhnya terhadap keputusan pembelian. Bagi peneliti selanjutnya, sebaiknya penelitian dilakukan dengan menambahkan variabel lain misalnya dengan memasukkan variabel lain seperti merek, jaminan/garansi, dan layanan pelengkap atau dapat juga mengembangkan indikatorindikator dari variabel yang digunakan dalam penelitian ini, sehingga dapat lebih memperkaya pengetahuan dan penelitian tentang keputusan pembelian smartphone.

\section{DAFTAR PUSTAKA}

Alana, Aditya Yesika, Wahyu Hidayat dan Handoyo Djoko W. 2012. "Pengaruh Citra Merek, Desain, dan Fitur Produk Terhadap Keputusan Pembelian Handphone Nokia (Studi 
Kasus pada Mahasiswa Universitas Diponegoro)”. Universitas Diponegoro, Semarang.

Ghozali, Imam. 2007. Aplikasi Analisis Multivariate dengan Program SPSS. Semarang : Badan Penerbit Universitas Diponegoro.

Kotler, Philip dan Gary Armstrong. 2008. Prinsip-Prinsip Pemasaran (Edisi 12). Jakarta : Erlangga.

Kotler, Philip dan Kevin Lane Keller, 2009. Manajemen Pemasaran (Edisi 13). Jakarta : Erlangga.

Kuncoro, Mudrajad. 2009. Metode Riset untuk Bisnis \& Ekonomi (Edisi 3). Jakarta : Erlangga.

Mowen, Jhon C dan Minor, M. 2007. Perilaku Konsumen. Jakarta : Erlangga.

Riduwan dan Akdon. 2013. Rumus dan Data dalam Analisis Statistika. Bandung : Alfabeta.

Setiadi, Nugroho J. 2008. Perilaku Konsumen. Jakarta : Prenada Media.

Sugiyono. 2012. Metode Penelitian Bisnis. Bandung : Alfabeta.

Suryani, Tati, 2013. Perilaku Konsumen di Era Internet dan Implikasinya pada Strategi Pemasaran. Yogyakarta : Graha Ilmu.

Swastha, Basu, 2006. Manajemen Penjualan, Edisi 3. Yogyakarta : BPFE.

Swastha, Basu dan Irawan, 2007. Manajemen Pemasaran Modern. Yogyakarta : Liberty.

Tjiptono, Fandy. 2007. Strategi Pemasaran. Malang : Bayumedia Pubishing.

Usman, Hardius dan Nurdin Sobari. 2013. Aplikasi Teknik Multivariate untuk Riset Pemasaran. Jakarta : PT. Raja Grafindo Persada. 